\title{
Dissociation, Distribution and Polymerization Constants for Dibutylphenacylphosphonate (HDBPP)
}

\author{
J. P. BRUNETTE, ${ }^{*}$ U. OLOFSSON, A. SELME and B. ALLARD
}

Department of Nuclear Chemistry, Chalmers University of Technology, S-412 96 Gothenburg, Sweden

The distribution of dibutylphenacylphosphonate between $1 \mathrm{M}(\mathrm{Na}, \mathrm{H}) \mathrm{ClO}_{4}$ and organic diluents ( $\mathrm{n}$ hexane, n-heptane, benzene, toluene) has been studied by a spectrophotometric method, as well as the dissociation in the aqueous phase and the diand trimerization in the organic phase. The following constants $\left(25^{\circ} \mathrm{C}\right)$ were obtained: Dissociation $\left(K_{\mathrm{a}}=\left[\mathrm{H}^{+}\right]\left[\mathrm{A}^{-}\right] /[\mathrm{HA}]\right): 12.30 \pm 0.03$; distribution $\left(K_{\mathrm{d}}=[\overline{\mathrm{HA}} /[\mathrm{HA}]): 29.8\left(\Delta H^{\circ}=16.8 \mathrm{~kJ} / \mathrm{mol}, T \Delta S^{\circ}\right.\right.$ $=25.2 \mathrm{~kJ} / \mathrm{mol} ; \mathrm{n}$-heptane), 35.0 (n-hexane), $1200 \pm 200$ (benzene) and $1400 \pm 200$ (toluene); dimerization $\left.\left(K_{\mathrm{n}}=[\overline{\mathrm{HA}})_{\mathrm{n}}\right] /[\overline{\mathrm{HA}}]^{\mathrm{n}}, \mathrm{n}=2\right): 7.95\left(\Delta H^{\circ}=\right.$ $-11.8 \mathrm{~kJ} / \mathrm{mol}, T \Delta S^{\circ}=-6.6 \mathrm{~kJ} / \mathrm{mol} ; \mathrm{n}$-heptane), 6.7 (n-hexane), and trimerization $(n=3): 210(n-$ heptane), 150 (n-hexane).

Although some metal complexes and metal extraction system using $\beta$-ketophosphonates as ligands or extractants have been studied ${ }^{1-12}$, very little information is available concerning the properties of these complexing agents in two-phase systems, i.e. distribution constants $\left(K_{\mathrm{d}}\right)$, dissociation constants $\left(K_{\mathrm{a}}\right)$ and possible polymerization constants $\left(K_{\mathrm{n}}\right)$. These parameters are required for the interpretation of metal extraction processes. This paper describes a determination of these constants for dibutylphenacylphosphonate [HDBPP; composition $\left.\mathrm{C}_{6} \mathrm{H}_{5} \mathrm{C}(\mathrm{O}) \mathrm{CH}_{2} \mathrm{P}(\mathrm{O})\left(\mathrm{OC}_{4} \mathrm{H}_{9}\right)_{2}\right]$ in aqueous $1 \mathrm{M}$ $\mathrm{NaClO}_{4}-$ n-hexane,n-heptane, benzeneand toluene systems.

\section{EVALUATION METHODS}

Neglecting any aggregation in the aqueous phase and any dissociation in the organic phase, an acidic

* On leave from the Laboratoire de Chimie Minérale, Ecole Nationale Supérieure de Chimie, B.P. 296 R8 67008 Strasbourg Cedex, France. extractant HA in a two-phase liquid system can generally be described by the following equilibria:

$$
\begin{aligned}
& \mathrm{HA} \rightleftharpoons \mathrm{H}^{+}+\mathrm{A}^{-} \quad\left(K_{\mathrm{a}}, \text { dissociation constant }\right) \\
& \mathrm{HA} \rightleftharpoons \overline{\mathrm{HA}} \quad\left(K_{\mathrm{d}}, \text { distribution constant }\right) \\
& n \overline{\mathrm{HA}} \rightleftharpoons(\overline{\mathrm{HA}})_{\mathrm{n}} \quad\left(K_{\mathrm{n}} \text {, polymerization constant }\right)
\end{aligned}
$$

(overlined symbols refer to species in the organic phase).

The distribution ratio $D$ is defined by

$D=[\overline{\mathrm{HA}}]_{\mathrm{tot}} /[\mathrm{HA}]_{\mathrm{tot}}$

giving eqn. (1).

$D=\left(K_{\mathrm{d}}+\sum_{2}^{\mathrm{n}} n K_{\mathrm{n}} \mathrm{K}_{\mathrm{d}}{ }^{n}[\mathrm{HA}]^{\mathrm{n}-1}\right) /\left(1+K_{\mathrm{a}}\left[\mathrm{H}^{+}\right]^{-1}\right)$

$\mathrm{K}_{d}$ and $\mathrm{K}_{n}$ determination. For $\mathrm{pH} \ll \mathrm{p} K_{\mathrm{a}}, D$ is independent of $\mathrm{pH}$ and eqn. (1) can be written as eqn. (2). A plot of $D v s$. [HA] permits a determination

$D=K_{\mathrm{d}}+\sum_{2}^{\mathrm{n}} n K_{\mathrm{n}} K_{\mathrm{d}}{ }^{n}[\mathrm{HA}]^{n-1}$

of the constants $K_{\mathrm{d}}$ and $K_{\mathrm{n}}$ with $K_{\mathrm{d}}=D([\mathrm{HA}]=0)$, assuming that $K_{\mathrm{d}}$ is constant, independently of [HA].

$\mathrm{K}_{\mathrm{a}}$ determination. For $[\mathrm{HA}] \rightarrow 0$, the aggregation of $\mathrm{HA}$ in the organic phase can generally be neglected and eqn. (1) can be written as

$\mathrm{D}=K_{\mathrm{d}}\left(1+K_{\mathrm{a}}\left[\mathrm{H}^{+}\right]^{-1}\right)^{-1}$

or eqn. (3). Thus, $\mathrm{pH} v s \cdot \log \left(K_{\mathrm{d}} D^{-1}-1\right)$ is a straight line with slope 1 and intercepts $\mathrm{p} K_{\mathrm{a}}$. (It is assumed that $K_{\mathrm{d}}$ is constant in the $\mathrm{pH}$ range studied.)

$\mathrm{pH}=\log \left(K_{\mathrm{d}} D^{-1}-1\right)+\mathrm{p} K_{\mathrm{a}}$ 


\section{EXPERIMENTAL}

Chemicals. Sodium perchlorate was prepared and purified according to conventional methods. HDBPP was prepared, purified and checked as described previously. ${ }^{9}$ All other chemicals were of p.a. quality and used without further purification.

Distribution measurements. The distribution of HDBPP between an aqueous sodium perchlorate solution and organic phases was studied in a thermostated vessel $\left( \pm 0.1^{\circ} \mathrm{C}\right)$. The two phases (with an initial HDBPP concentration in the organic phase between $10^{-4}$ and $1.7 \times 10^{-3} \mathrm{M}$ ) were vigorously stirred for one hour and then allowed to separate by gravity. For each distribution ratio determination, an aliquot of each phase was withdrawn and diluted with ethanol and the UV spectrum recorded. The UV absorption spectrum of HDBPP in ethanol contains a strong absorption band at $246 \mathrm{~nm}$ with a maximum extinction coefficient $\left(\varepsilon_{\max }\right)$ of $13000 \mathrm{M}^{-1}$ $\mathrm{cm}^{-1}$ and a shoulder at $280 \mathrm{~nm}$ with $\varepsilon_{\max } \sim 1200$ $\mathrm{M}^{-1} \mathrm{~cm}^{-1}$. The Beer-Lambert law was checked and the $246 \mathrm{~nm}$ band used to determine HDBPP concentrations in the two phases. When benzene and toluene were used as solvents, the measurements had to be corrected taking into account the absorption of the solvents themselves (this explains the low relative precision of the corresponding measurements).

In order to check the direct measurements of low HDBPP concentrations in highly dissociated systems, the total aqueous HDBPP concentration was calculated from the difference between the
Table 1. Distribution and polymerization constants.

\begin{tabular}{lllll}
\hline Diluent & $t,{ }^{\circ} \mathrm{C}$ & $K_{\mathrm{d}}$ & $K_{2}$ & $K_{3}$ \\
\hline & 10.0 & 19.0 & 10.1 & 215 \\
n-Heptane & 24.9 & 29.8 & 7.95 & 210 \\
& 39.4 & 37.3 & 6.3 & 230 \\
n-Hexane & 25.0 & 35.0 & 6.7 & 150 \\
Benzene & 25.0 & $1200 \pm 200$ & - & - \\
Toluene & 25.0 & $1400 \pm 200$ & - & - \\
\hline
\end{tabular}

added HDBPP and the measured organic HDBPP concentration. The calculated $[\mathrm{HDBPP}]_{\text {tot }}$-values were verified by direct UV measurements on the aqueous solutions which were $\mathrm{pH}$ adjusted after separation of the phases to suppress the HDBPP dissociation effect.

All UV measurements were performed on a Perkin-Elmer 551 spectrophotometer using $1 \mathrm{~cm}$ quartz cells.

\section{RESULTS AND DISCUSSIONS}

$\mathrm{K}_{d}$ and $\mathrm{K}_{n}$ determinations. The determinations of distribution constants and polymerization constants were performed using an aqueous phase of $1 \mathrm{M}$ $(\mathrm{Na}, \mathrm{H}) \mathrm{ClO}_{4}$ at $\mathrm{pH} 4$, and n-hexane, n-heptane, benzene and toluene as organic diluents. Fig. 1 shows a plot of $D v$ s. [HDBPP] at different temperatures for $\mathrm{n}$-heptane and $\mathrm{n}$-hexane. According to

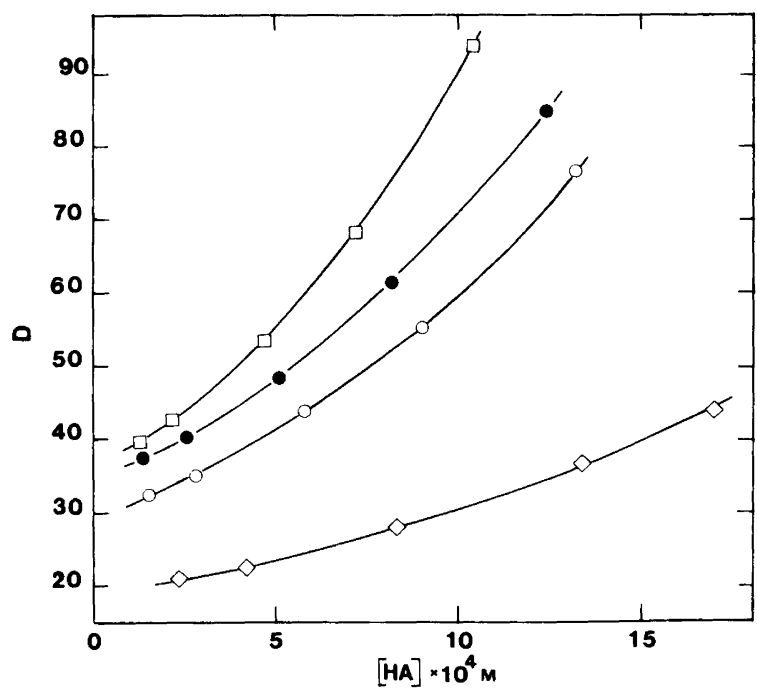

Fig. 1. Distribution ratios of $\mathrm{HDBPP}$ in $1 \mathrm{M}(\mathrm{Na}, \mathrm{H}) \mathrm{ClO}_{4}-\mathrm{n}$-heptane and n-hexane. $\square, 39.4^{\circ} \mathrm{C} ; \mathrm{O}, 24,9^{\circ} \mathrm{C}$; $\diamond, 10.0^{\circ} \mathrm{C}-\mathrm{n}$-heptane; $\boldsymbol{\theta}, 25.0^{\circ} \mathrm{C}-\mathrm{n}$-hexane. 


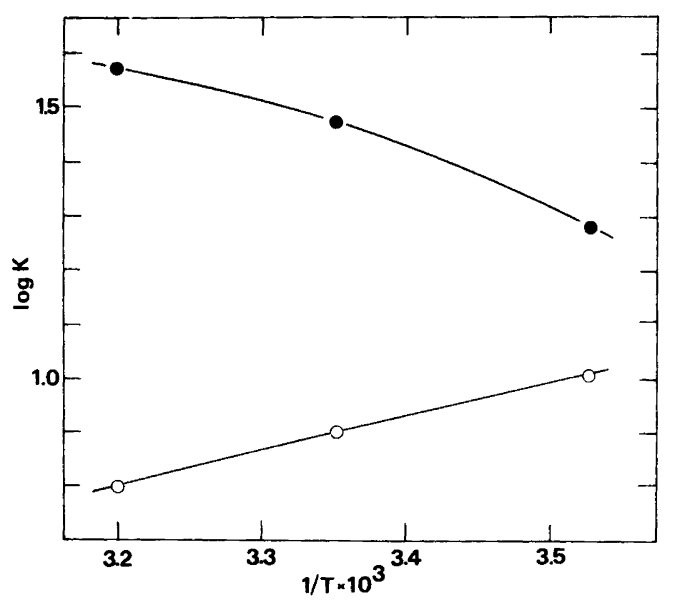

Fig. 2. $\log K_{2}$ and $\log K_{d}$ vs. $1 / T . \bigcirc, \log K_{2}$; ○, $\log$ $K_{\mathrm{d}}-$ n-heptane.

eqn. (2), the non-linearity of the curves is consistent with a polymerization $(n>2)$. Assuming a trimerization of HDBPP in $n$-heptane, the experimental results can be well described by eqns. (4) (6). A similar result is obtained for n-hexane;

$D\left(10^{\circ} \mathrm{C}\right)=19.0+7330[\mathrm{HDBPP}]+$ $4.38 \times 10^{6}[\mathrm{HDBPP}]^{2}$

$D\left(24.9^{\circ} \mathrm{C}\right)=29.8+13800[\mathrm{HDBPP}]+$ $16.3 \times 10^{6}[\mathrm{HDBPP}]^{2}$

$D\left(39.4^{\circ} \mathrm{C}\right)=37.3+17500[$ HDBPP $]+$ $35.8 \times 10^{6}[\mathrm{HDBPP}]^{2}$

$D\left(25.0^{\circ} \mathrm{C}\right)=35.0+16400[\mathrm{HDBPP}]+$ $19.5 \times 10^{6}[\mathrm{HDBPP}]^{2}$

eqn. (7). Using eqns. $2,4,5,6$ and $7, K_{d}, K_{2}$ and $K_{3}$ were calculated, Table 1, Fig. 2. For the benzene and toluene systems, the distribution constants were independent of [HDBPP] (in the concentration range $0<[$ HDBPP $]<0.6 \mathrm{M}$ ), which shows that HDBPP is not aggregated in these dilutents. This result is consistent with previous observations from cryoscopic measurements ${ }^{9}$ that HDBPP is monomeric in benzene.

The influence of $\mathrm{pH}$ on the distribution constant (in the $1 \mathrm{M}(\mathrm{Na}, \mathrm{H}) \mathrm{ClO}_{4}-\mathrm{n}$-heptane system, $25^{\circ} \mathrm{C}$ ) has also been investigated. For $2<\mathrm{pH}<10$, other parameters kept constant, the distribution ratio is independent of $\mathrm{pH}$. (The UV spectra of the two phases are constant). For the studied $\mathrm{pH}$ range no

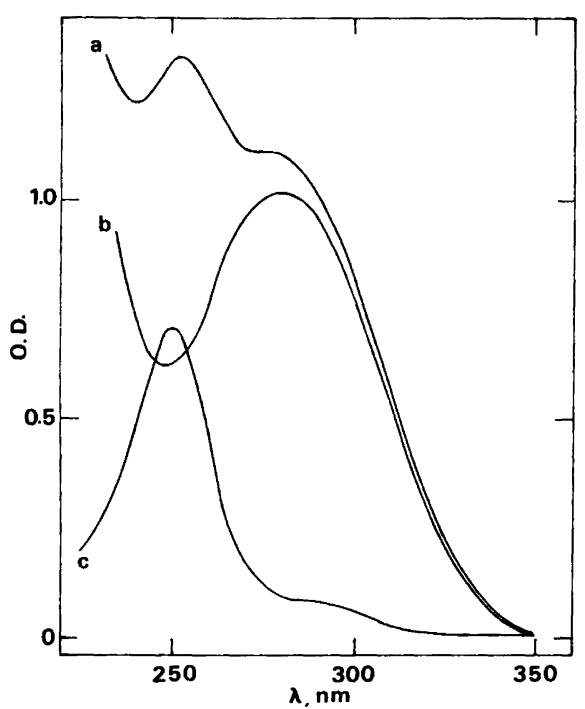

Fig. 3. UV spectra of HDBPP-DBPP- (optical density, O. D., vs. wave length, $\lambda$ ). a. Aqueous phase $1 \mathrm{M}(\mathrm{Na}, \mathrm{H}) \mathrm{ClO}_{4}, \mathrm{pH} 12.66$, after shaking with a 0.00205 M HDBPP - n-heptane solution. b. DBPPin aq, $14.0 \times 10^{-5} \mathrm{M} ; \varepsilon_{280}=7000 \mathrm{M}^{-1} \mathrm{~cm}^{-1}$. c. HDBPP in $n$-heptane, $6.1 \times 10^{-5} \mathrm{M} ; \varepsilon_{250}=$ $11200 \mathrm{M}^{-1} \mathrm{~cm}^{-1}$.

detectable dissociation of HDBPP occurs.

The hypothesis of extraction of $\mathrm{HClO}_{4}$ by HDBPP as an explanation of the non-linearity of the curves $D$ vs. [HDBPP] (Fig. 1) can be eliminated $\left(\mathrm{HClO}_{4}\right.$ extraction would only occur at lower $\mathrm{pH}$ ).

$p \mathrm{~K}_{\mathrm{a}}$ determination. When $\mathrm{pH}$ is increased over 10 , the UV spectra of the aqueous phases are progressively changed as an effect of HDBPP dissociation. Each spectrum can be decomposed into two spectra corresponding to HDBPP and DBPP(Fig. 3). The UV spectrum of DBPP ${ }^{-}$has a broad adsorption band at $280 \mathrm{~nm}$ with an $\varepsilon_{\max }$ of 7000 $\mathrm{M}^{-1} \mathrm{~cm}^{-1}$. If $\mathrm{pH}$ is adjusted back to $\mathrm{pH}<10$, the spectrum of undissociated HDBPP is quantitatively recovered which shows the reversibility of the dissociation and permits quantitatively measurements of aqueous [HDBPP] $]_{\text {tot }}$.

The curve pH vs. $\log \left(K_{\mathrm{d}} D^{-1}-1\right)$ is given in Fig. 4. The observed slope of 1.03 is close to the theoretical value of 1 . The $\mathrm{p} K_{\mathrm{a}}$-value from the intercept is $12.30 \pm 0.03$, which is higher than for most of the $\beta$-diketones (e.g. for acetylacetone). ${ }^{13}$ Thus, HDBPP would be expected to act as a chelating 


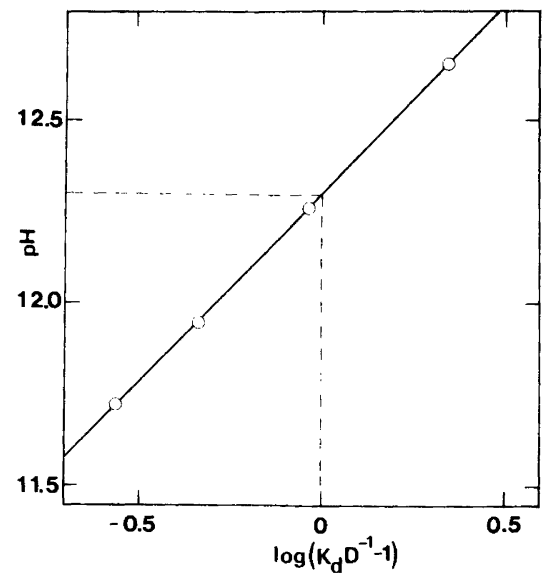

Fig. 4. Dissociation constant of HDBPP at $25^{\circ} \mathrm{C}$. (pH vs. $\log \left(K_{\mathrm{d}} D^{-1}-1\right)$. Aqueous phase: $1 \mathrm{M}(\mathrm{Na}, \mathrm{H})$ $\mathrm{ClO}_{4}$; organic phase n-heptane.

extractant in a higher $\mathrm{pH}$-range than e.g. acetylacetone.

Temperature effects. From the temperature dependence of $K_{\mathrm{d}}$ and $K_{2}$ in the n-heptane system (cf. Table 1 and Fig. 2) and according to the relationship $\Delta G^{\circ}=\Delta H^{\circ}-T \Delta S^{\circ}=-R T \ln K$, the following thermodynamic constants were calculated $\left(25^{\circ} \mathrm{C}\right)$ :

Distribution: $\Delta H^{\circ}=16.8 \pm 1.2 \mathrm{~kJ} / \mathrm{mol}, T \Delta S^{\circ}=$ $25.2 \pm 1.2 \mathrm{~kJ} / \mathrm{mol}$.

Dimerization: $\Delta H^{\circ}=-11.8 \pm 1.0 \mathrm{~kJ} / \mathrm{mol}, T \Delta S^{\circ}=$ $-6.6 \pm 1.0 \mathrm{~kJ} / \mathrm{mol}$.

(The uncertainty in the $K_{3}$-values is too large to allow any calculation of $\Delta H^{\circ}$ - and $T \Delta S^{\circ}$-values for the trimerization.) Thus, it is evident that a temperature increase favours a transfer of HDBPP from the aqueous phase to the $n$-heptane phase, which would be expected, considering the similarity with the $\beta$-diketones, ${ }^{13}$ but disfavours the dimerization in the organic phase.

Acknowledgement. This work was partly financed by the Swedish Natural Science Research Council (NFR).

\section{REFERENCES}

1. Warren, C. J. J. Inorg. Nucl. Chem. 23 (1961) 103.

2. Cotton, F. A. and Schunn, R. A. J. Am. Chem. Soc. 85 (1963) 2394.

3. Lestas, C. N. and Truter, M. R. J. Chem. Soc. $A$ (1971) 738 .
4. Youinou, M. T. and Guerchais, J. E. Inorg. Chem. Acta 19 (1976) 257.

5. Youinou, M. T., Guerchais, J. E., Louër, M. E. and Grandjea, D. Inorg. Chem. 16 (1977) 872.

6. Sevdic, D. and Meider-Gorican, H. J. Less. Common Met. 27 (1972) 403.

7. Bronzan, P. and Meider-Gorican, H. J. Less Common Met. 29 (1972) 407.

8. Youinou, M. T. and Guerchais, J. E. J. Chem. Soc. Dalton Trans (1976) 293.

9. Martin, J. L. and Leroy, M. J. F. J. Chem. Res. $S$ (1978) 88.

10. Brunette, J. P., Leroy, M. J. F., Ceccaroli, B. and Alstad, J. Acta Chem. Scand. A 32 (1978) 415.

11. Alstad, J., Ceccaroli, B., Brunette, J. P. and Leroy, M. J. F. Proc. Int. Solvent Extraction Conf., ISEC 80, Liege 1980, p. 80-48.

12. Olofsson, U., Brunette, J. P., Allard, B. and Selme, A. Proc. Int. Solvent Extraction Conf., ISEC 80, Liege 1980, p. 80-6.

13. Liljenzin, J. O. Acta Chem. Scand. 23 (1969) 3592.

Received December 14, 1981. 